\title{
Solid state gas sensors: improvement through material engineering
}

\author{
Sang Do Han, Ghenadii Korotcenkov*ץ, and Jihye Gwak
}

\begin{abstract}
Different methods of material engineering, used for improvement of solid state gas sensors parameters are reviewed in this report. The wide possibilities of material engineering in optimization of gas sensing properties were demonstrated on the example of $\mathrm{SnO}_{2}, \mathrm{TiO}_{2}$ and $\mathrm{In}_{2} \mathrm{O}_{3}$-based sensors.
\end{abstract}

Key Words : gas sensors; metal oxides; $\mathrm{SnO}_{2}, \mathrm{In}_{2} \mathrm{O}_{3}, \mathrm{TiO}_{2}$ material engineering; optimization

\section{Introduction}

At present, material engineering of metal oxide films is one of the most effective methods used for optimization of solid state gas sensors. The considerable improvement of such operating parameters as sensor signal, selectivity, stability and the rate of sensor response can be achieved due to optimization of structural, bulk and surface properties of applied metal oxides. Different aspects of material engineering have been studied in many papers ${ }^{[1-4]}$. In this report we have presented our view on above-mentioned problem. For discussing possibilities of material engineering for sensor response control we mainly used the results obtained for $\mathrm{SnO}_{2}, \mathrm{In}_{2} \mathrm{O}_{3}$ and $\mathrm{TiO}_{2}$-based devices. These metal oxides are materials mostly used for design of solid state gas sensor and therefore the determination of the nature of processes, controlling gas sensing effects with participation of those metal oxides, is very important for determination a real prospects of these materials for application $\mathrm{s}^{[5-11]}$.

There are many types of solid state sensors, which can be used for gas detection. However, we will focus on chemiresistors, or conductometric gas sensors, and on catalytic type gas sensors. It means that we will discuss sensors, which mainly operate on the base of surface reactions.

Despite some disadvantages of these sensors(Table 1), they have excellent sensitivity, very short response time, low cost, and very good suitability for design of portable

Korea Institute of Energy Research

* Gwangju Institute of Science and Technology

'Corresponding author: ghkoro@yahoo.com

(Received: March 2, 2009, Accepted: April 9, 2009) instruments, which compensate their disadvantages and open great possibilities for those sensors' application in alarm systems, portable instruments and electronic nose.

\section{Parameters of metal oxides, which control their gas sensing properties}

Conducted research have shown that gas sensing effect in metal oxides is very complicated phenomenon, which practically depends on all metal oxide parameters(Fig. 1) ${ }^{[4,6,7]}$.

Carried-out analysis has shown that influence of above mentioned parameters on gas sensing characteristics takes place through the change of such parameters as effective area of intergrain and interagglomerate contacts; energetic parameters of adsorption/desorption

Table 1. Gas Sensor Comparison

\begin{tabular}{|c|c|c|c|c|c|}
\hline \multirow{2}{*}{ Parameter } & \multicolumn{5}{|c|}{ Type of gas sensors } \\
\hline & (1) & (2) & (3) & (4) & (5) \\
\hline Sensitivity & $\mathrm{e}$ & $\mathrm{g}$ & $\mathrm{g}$ & $\mathrm{b}$ & $\mathrm{e}$ \\
\hline Accuracy & $\mathrm{g}$ & $g$ & $\mathrm{~g}$ & $g$ & $\mathrm{e}$ \\
\hline Selectivity & $\mathrm{p}$ & $\mathrm{b}$ & $\mathrm{g}$ & $\mathrm{b}$ & e \\
\hline Response time & $\mathrm{e}$ & $\mathrm{g}$ & $\mathrm{p}$ & $\mathrm{g}$ & $\mathrm{p}$ \\
\hline Stability & $\mathrm{g}$ & g & $\mathrm{b}$ & g & $\mathrm{g}$ \\
\hline Durability & $\mathrm{g}$ & g & $\mathrm{p}$ & g & e \\
\hline Maintenance & $\mathrm{e}$ & e & $\mathrm{g}$ & $\mathrm{g}$ & $\mathrm{p}$ \\
\hline Cost & $\mathrm{e}$ & $\mathrm{e}$ & $\mathrm{g}$ & $\mathrm{g}$ & $\mathrm{p}$ \\
\hline $\begin{array}{c}\text { Suitability to } \\
\text { portable divices }\end{array}$ & e & $\mathrm{g}$ & $\mathrm{g}$ & $\mathrm{g}$ & $\mathrm{b}$ \\
\hline
\end{tabular}

e: excellent; g: good; p: poor; b: bad

(1) semiconductor; (2) catalytical combustions; (3) electrochemical; (4) thermal conductive; (5) infra-red adsorption. 


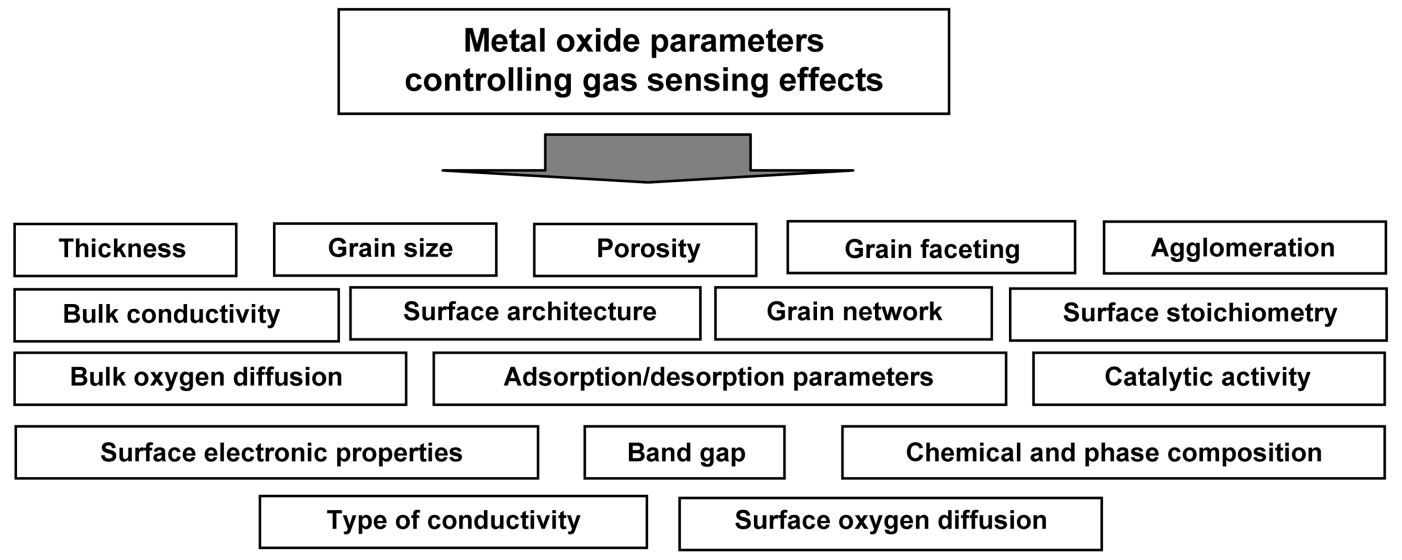

Fig. 1. Diagram showing metal oxide parameters, which control their gas sensing properties.

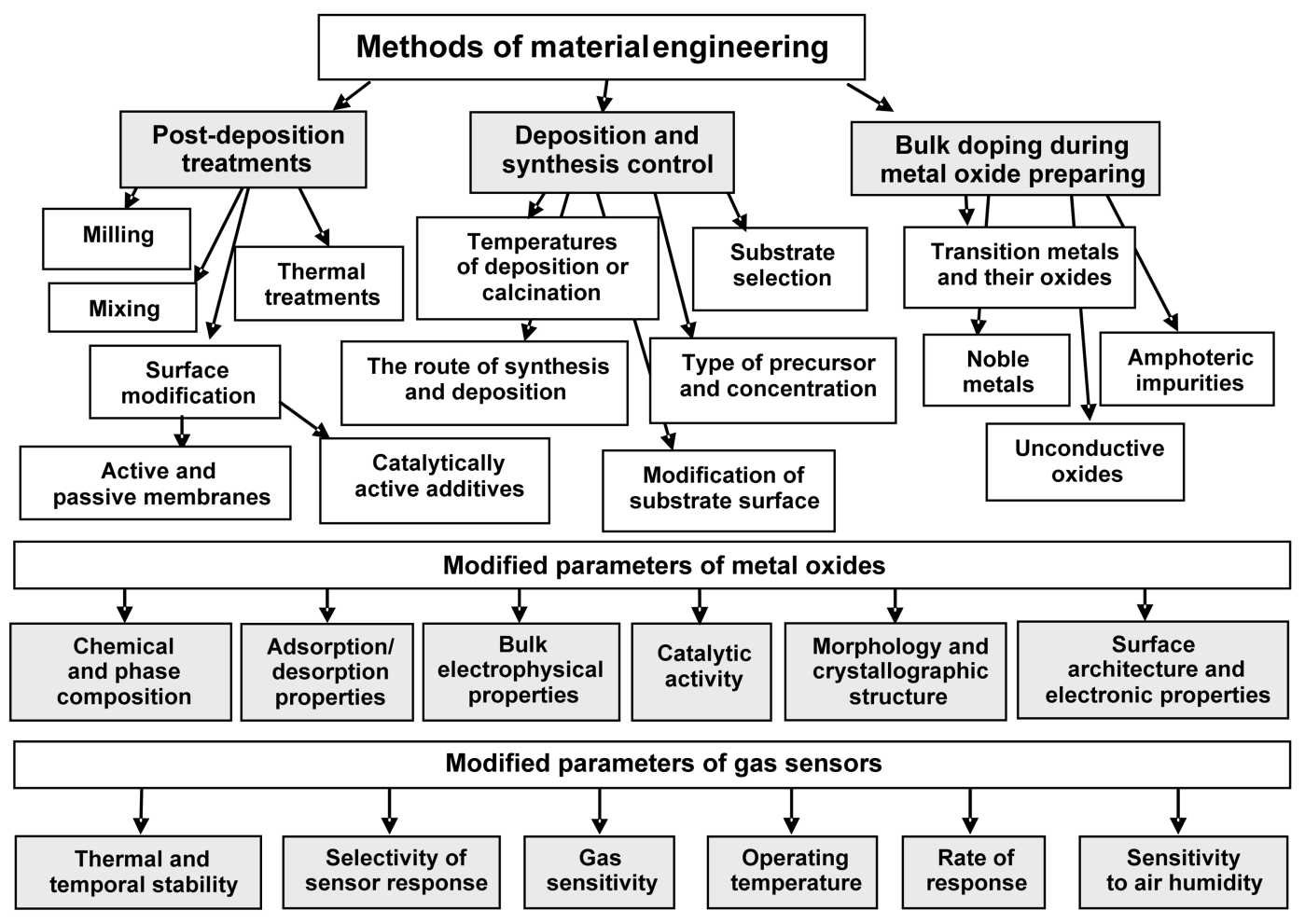

Fig. 2. The diagram illustrating approaches used for optimization of metal oxide properties.

processes; number of surface sites; concentration of charge carriers; initial surface potential; coordination number of metal atoms on the surface, etc ${ }^{[7,12]}$.

\section{Methods of material engineering}

Different processes affecting parameters of oxide sen- sors are summarized in the diagram shown in Fig. 2. One can see that there are a great number of methods for optimization of sensor parameters ${ }^{[13-17]}$. The effectiveness of above mentioned methods one can estimate on the base of the results is presented in Refs. ${ }^{[4]}$. It was shown that deposition parameter control, post deposition treatments and doping during synthesis and depo- 


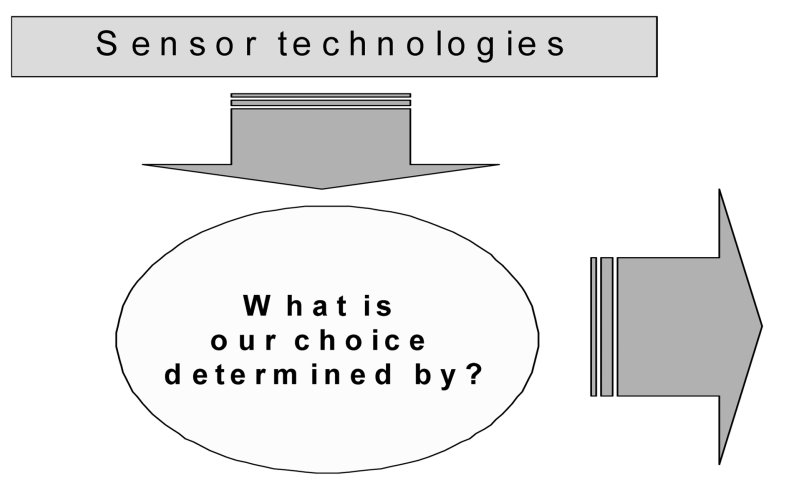

\begin{tabular}{|l|}
\hline I. Device destination \\
\hline II. The nature of detected gas \\
\hline IV. Required sensitivity \\
\hline III. Detection m echanis, \\
realized during gas response \\
\hline V. Exploitation conditions \\
\hline VI. Required rate of as \\
response \\
\hline VII. Gas response selectivity \\
\hline VIII. Compatibility ith \\
peripheral measuring devices \\
\hline
\end{tabular}

Fig. 3. Diagram illustrating the factors, which determine the choice of sensor technologies.

sition processes really influence all properties of metal oxides, important for gas sensor applications.

For example, the increase of pyrolysis temperature during $\operatorname{In}_{2} \mathrm{O}_{3}$ deposition reduces the influence of water vapor on the conductivity of $\mathrm{In}_{2} \mathrm{O}_{3}$ and $\mathrm{SnO}_{2}$ films and respectively on sensor response ${ }^{[18]}$. The surface modification by noble metals promotes the improvement of sensitivity and decrease of response and recovery times ${ }^{[19-23]}$. The use of one-dimensional metal oxides improves catalytic activity. The metal oxide doping by transition metal modifies the morphology of deposited films, etc. ${ }^{[2]}$ We established that the last method of material engineering is the most unpredictable one. Depending on both the concentrations of additives and crystallization parameters, it can take place a simultaneous structure modification, accompanied by the grain size change, appearance of second phase in base oxide $^{[24-26]}$, i.e. heterostructures of various forms, and the change of electrophysical and surface properties of metal oxides ${ }^{[6]}$. It means that trying to find parameters of metal oxide doping for achievement of optimal gas sensing characteristics, we should consider the change of all parameters of designed metal oxides.

\section{What determines the selection of sensor technologies}

Based on conducted research, it was established the following. The choice of either methods and technological parameters of metal oxide synthesis and deposition for achievement necessary electrophysical and structural properties should take into account a great number of requirements presented to designed sensor(Fig. 3$)^{[4]}$.
The configuration of designed sensors is also important factor influencing our choice. For example oneelectrode and two-electrode sensors have different requirements to material resistance for their optimal functioning ${ }^{[27]}$. At the same time for catalytic combustion type sensors we do not have any requirements to the material resistance.

\section{Remarks}

The elaboration of sensors with optimal gas sensing characteristics is very complicate task. Besides, in spite of great technological possibilities, there is no universal decision for simultaneous optimization of all sensor parameters. As a rule, an improvement of one parameter is accompanied by worsening of another one.

For example, the smaller the crystallite size is, the higher the sensitivity is ${ }^{[28]}$, but at the same time the stability of gas sensor parameters is lower ${ }^{[29]}$. It means that the decrease of the grain size improves sensitivity and decreases the thermal and temporal stability of designed gas sensor. Therefore on all stages of gas sensor design and fabrication one should seek a compromise between different parameters of designed gas sensors: between sensitivity and stability; between selectivity and sensitivity; between stability, sensitivity and sensor cost; and so on.

As the comparison of various metal oxides has shown, there is no universal material suitable for application in all types of gas sensors. For example, even analyzed tin and indium oxides have both advantages and disadvantages for application in different gas sensors ${ }^{[30]}$. Therefore the choice of one or other material 
would be also determined by exploitation conditions, and the requirements to sensors.

\section{Acknowledgements}

This work was supported by The Korea Research Foundation and The Korean Federation of Science and Technology Socities Grant funded by Korea Government (MOEHRD, Basic Research Promotion Fund). G Korotcenkov is thankful to Korean BK21 Program for support of his research.

\section{References}

[1] N. Yamazoe, "New approaches for improving semiconductor gas sensors", Sens. Actuators B, vol. 5, no. 1-4, pp. 7-19, 1991.

[2] D.E. Williams, "Semiconducting oxides as gas-sensitive resistors", Sens. Actuators B, vol. 57, no. 13, pp. 1-16, 1999.

[3] K.D. Schierbaum, "Engineering of oxide surfaces and metal/oxide interfaces for chemical sensors: recent trends", Sens. Actuators B, vol. 24, no. 1-3, pp. 239-247, 1995.

[4] G. Korotcenkov, "Gas response control through structural and chemical modification of metal oxide films: state of the art and approaches", Sens. Actuators $B$, vol. 107, no. 1, pp. 209-232, 2005.

[5] N. Barsan, M. Schweizer-Berberich and W. Gopel, "Fundamental and practical aspects in the design of nanoscaled $\mathrm{SnO}_{2}$ gas sensors: a status report", $J$. Anal. Chem., vol. 365, no. 4, pp. 287-304, 1999.

[6] G. Korotcenkov, "The role of morphology and crystallographic structure of metal oxides in response of conductometric-type gas sensors", Mater. Sci. Eng. $R$, vol. 61 no. 1-6, pp. 1-39, 2008.

[7] G. Korotcenkov, "Metal oxides for solid-state gas sensors: What determines our choice?", Mater. Sci. Eng. B, vol. 139, no.1, pp. 1-23, 2007.

[8] G. Korotcenkov, V. Brinzari, J.R. Stetter, I. Blinov and V. Blaja, "The nature of processes controlling the kinetics of indium oxide-based thin film gas sensor response", Sens Actuators B, vol. 128, no. 1, pp. 51-63, 2007.

[9] M.O. Park, S.D. Choi, B.K. Min and J.W. Lim, "Long-term stabilized metal oxide-doped $\mathrm{SnO}_{2}$ sensors", J. Kor. Sensors Soc., vol. 17, no. 4, pp. 295302, 2008.

[10] H.G. Moon, S.J. Yoon, H.H. Park and J.S. Kim, "Growth mechanism of three dimensionally struc- tured $\mathrm{TiO}_{2}$ thin film for gas sensors", J. Kor. Sensors Soc., vol. 18, no. 2, pp. 110-115, 2009.

[11] D.U. Hong, C.H. Han, S.D. Han, J. Gwak and S.Y. Lee, "Catalytic combustion type hydrogen gas sensor using $\mathrm{TiO}_{2}$ and UV LED", J. Kor. Sensors Soc., vol. 16, no. 1, pp. 7-10, 2007.

[12] V. Brinzari, G. Korotcenkov and V. Golovanov, "Factors influencing the gas sensing characteristics of tin dioxide films deposited by spray pyrolysis: understanding and possibilities of control", Thin Solid Films, vol. 391, no. 2, pp. 167-175, 2001.

[13] G. Korotcenkov, V. Macsanov, V. Tolstoy, V. Brinzari, J. Schwank and G. Faglia, "Structural and gas response characterization of nano-size $\mathrm{SnO}_{2}$ films deposited by SILD method", Sens. Actuators B, vol. 96, no. 3, pp. 602-609, 2003.

[14] D. Kohl, "The role of noble metals in the chemistry of solid-state gas sensors", Sens. Actuators B, vol. 1, no. 1-6, pp. 158-165, 1990.

[15] C. Pijolat, J.P. Viricelle, G. Tournier and P. Montmeat, "Application of membranes and filtering films for gas sensors improvements", Thin Solid Films, vol. 490, no. 1, pp. 7-16, 2005.

[16] H. Yamaura, K. Moriya, N. Miura and N. Yamazoe, "Mechanism of sensitivity promotion in $\mathrm{CO}$ sensor using indium oxide and cobalt oxide", Sens. Actuators $B$, vol. 65 , no. 1-3, pp. 39-41, 2000.

[17] G. Sberveglieri, "Recent developments in semiconducting thin-film gas sensors", Sens. Actuators B, vol. 23, no. 2-3, pp. 103-109, 1995.

[18] G. Korotcenkov, I. Blinov, V. Brinzari and J.R. Stetter, "Effect of air humidity on gas response of $\mathrm{SnO}_{2}$ thin film ozone sensors", Sens. Actuators B, vol. 122, no. 2, pp. 519.-526, 2007.

[19] C.-H. Han S.-D. Han and S.P. Khatkar, "Enhancement of $\mathrm{H}_{2}$-sensing properties of $\mathrm{F}$-doped $\mathrm{SnO}_{2}$ sensor by surface modification with $\mathrm{SiO}_{2}$ ", Sensors, vol. 6, no. 5, pp. 492-502, 2006.

[20] C.H. Han, D.W. Hong, I.J. Kim, J. Gwak, S.D. Han and K.C. Singh, "Synthesis of Pd or Pt/titanate nanotube and its application to catalytic type hydrogen gas sensor", Sens. Actuators B, vol. 128, no. 1, pp. 320-325, 2007.

[21] G. Korotcenkov, V. Brinzari, Y. Boris, M. Ivanov, J. Schwank and J. Morante, "Influence of surface Pd doping on gas sensing characteristics of $\mathrm{SnO}_{2}$ thin films deposited by spray pirolysis", Thin Solid Films, vol. 436, no. 1, pp. 119-126, 2003.

[22] I.J. Kim, S.D. Han, C.H. Han, J. Gwak, D.U. Hong, D. Jakhar, K.C. Singh and J.S. Wang, "Development of micro hydrogen gas sensor with $\mathrm{SnO}_{2-}$ 
$\mathrm{Ag}_{2} \mathrm{O}-\mathrm{PtO}_{\mathrm{x}}$ composite using MEMS process", Sens. Actuatores B, vol. 127, no. 2, pp. 441-446, 2007.

[23] I.J. Kim, S.D. Han, C.H. Han, J. Gwak, H.D. Lee and J.S. Wang, "Micro semiconductor CO sensors based on indium-doped tin dioxide nanocrystalline powders", Sensors, vol. 6, no. 5, pp. 526-535, 2006.

[24] G. Korotcenkov, V. Brinzari and I. Boris, "( $\mathrm{Cu}, \mathrm{Fe}$, Co or Ni)-doped $\mathrm{SnO}_{2}$ films deposited by spray pyrolysis: Doping influence on film morphology", J. Mater. Sci., vol. 43, no. 8, pp. 2761-2770, 2008.

[25] V. Brinzari, G. Korotcenkov, V. Golovanov, J. Schwank, V. Lantto and S. Saukko, "Morphological rank of nano-scale tin dioxide films deposited by spray pyrolysis from $\mathrm{SnCl}_{4} \cdot 5 \mathrm{H}_{2} \mathrm{O}$ water solution", Thin Solid Films, vol. 408, no. 1-2, pp. 51-58, 2002.

[26] G. Korotcenkov, A. Cornet, E. Rossinyol, J. Arbiol, V. Brinzari and Y. Blinov, "Faceting characterization of tin dioxide nanocrystals deposited by spray pyrolysis from stannic chloride water solution", Thin
Solid Films, vol. 471, no. 1-2, pp. 310-319, 2005.

[27] G. Korotcenkov, "Practical aspects in design of oneelectrode semiconductor gas sensors: Status report", Sens. Actuators B, vol. 121, no. 2, pp. 664-678, 2007.

[28] G. Korotcenkov, V. Brinzari, A. Cerneavschi, M. Ivanov, V. Golovanov, A. Cornet, J. Morante, A. Cabot and J. Arbiol, "The influence of film structure on $\mathrm{In}_{2} \mathrm{O}_{3}$ gas response", Thin Solid Films, vol. 460, no. 1-2, pp. 315-323, 2004.

[29] G. Korotcenkov, V. Brinzari, M. Ivanov, A. Cerneavschi, J. Rodriguez, A. Cirera, A. Cornet and J. Morante, "Structural stability of indium oxide films deposited by spray pyrolysis during thermal annealing", Thin Solid Films, vol. 479, no. 1-2, pp. 38-51, 2005.

[30] G. Korotcenkov and J.R. Stetter, "Comparative study of $\mathrm{SnO}_{2-}$ and $\mathrm{In}_{2} \mathrm{O}_{3^{-}}$based ozone sensors", ECS Transactions, vol. 6, no. 20, pp. 29-41, 2008.

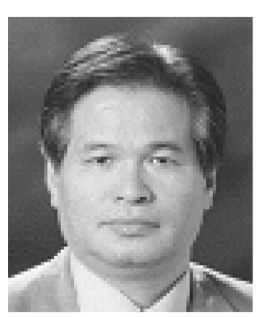

\section{Sang-Do Han}

- See p. 10 of $\mathbb{J}^{J}$. Kor. Sensors Soc., vol. 16 , no. $1 \unlhd$

- (present) President of The Korean Sensors Society

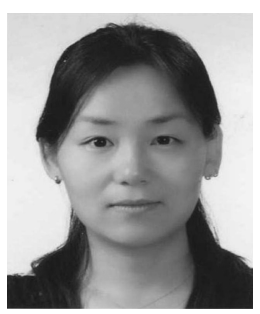

\section{Jihye Gwak}

- See p. 10 of 『J. Kor. Sensors Soc., vol. 16 , no. $1 \Perp$

- (present) Senior Researcher of Photovoltaic Research Center at KIER

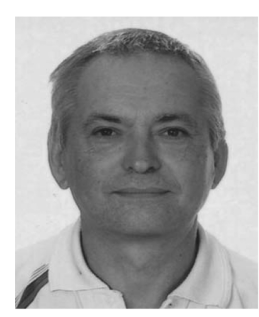

\section{Ghenadii Korotcenkov}

- 1976: Ph.D. in Physics \& Tech. of Semiconductor Matarials at Polytechnic Institute, Chisinau, Moldova

-1990: Dr. of Science(Dr. Habilitat) in Physics at Institute of Applied Physics, Academy of Science of Moldova

- 1974 1991: Scientific Researcher of Polytechnic Institute, Chisinau, Moldova

- 1991 present: Chief Scientific Researcher of Technical University of Moldova

-2007 2008: Visiting Scientist(BrainPool Program), Korea Institute of Energy Research

- 2008 present: Research Professor, Department of Material Science and Engineering, Gwangju Institute of Science and Technology 